\title{
Dipyridamole reduces penile apoptosis in a rat model of post-prostatectomy erectile dysfunction
}

Omer Kutlu 1,2, Ersagun Karaguzel ${ }^{2}$, Ali Ertan Okatan ${ }^{2}$, Ahmet Mentese ${ }^{3}$, Esin Yulug ${ }^{4}$, Ilke Onur Kazaz ${ }^{2}$, Selcuk Kutlu ${ }^{5}$, Eyup Dil ${ }^{2}$, Huseyin Eren ${ }^{2}$, Ahmet Alver ${ }^{6}$

1 Department of Urology, School of Medicine, Akdeniz University, Antalya, Turkey; ${ }^{2}$ Department of Urology School of Medicine, Karadeniz Technical University, Trabzon, Turkey; ${ }^{3}$ Program of Medical Laboratory Techniques, Vocational School of Health Sciences. Karadeniz Technical University, Trabzon, Turkey; ${ }^{4}$ Department of Histology and Embryology, School of Medicine, Karadeniz Technical University, Trabzon, Turkey; ${ }^{5}$ Department of Urology, Aydin State Hospital, Aydin, Turkey; ${ }^{6}$ Department of Biochemistry, School of Medicine, Karadeniz Technical University, Trabzon, Turkey

\section{ABSTRACT}

Purpose: Despite the nerve-sparing technique, many patients suffer from erectile dysfunction after radical prostatectomy (RP) due to cavernous nerve injury. The aim of this study was to evaluate dipyridamole as a potential treatment agent of post-radical prostatectomy erectile dysfunction.

Material and methods: A total of 18 male Sprague-Dawley rats were randomized into three experimental Groups (SHAM+DMSO, BCNI+DMSO and BCNI+DIP). An animal model of bilateral cavernous nerve crush injury (BCNI) was established to mimic the partial nerve damage during nerve-sparing RP. After creating of BCNI, dimethyl sulphoxide (DMSO) was administered transperitoneally as a vehicle to SHAM+DMSO and BCNI+DMSO Groups. BCNI+DIP Group received dipyiridamole (10mg/kg/day) as a solution in DMSO for 15 days. Afterwards, rats were evaluated for in vivo erectile response to cavernous nerve stimulation. Penile tissues were also analyzed biochemically for transforming growth factor- $\beta 1$ (TGF- $\beta 1$ ) level. Penile corporal apoptosis was determined by TUNEL method.

Results: Erectile response was decreased in rats with BCNI and there was no significant improvement with dipyridamole treatment. TGF- $\beta 1$ levels were increased in rats with BCNI and decreased with dipyridamole treatment. Dipyridamole led to reduced penile apoptosis in rats with BCNI and there was no significant difference when compared to sham operated rats.

Conclusions: Although fifteen-day dipyridamole treatment has failed to improve erectile function in rats with BCNI, the decline in both TGF- $\beta 1$ levels and apoptotic indices with treatment may be helpful in protecting penile morphology after cavernous nerve injury.

\section{ARTICLE INFO}

\section{Keywords:}

Erectile Dysfunction;

Dipyridamole; Penis

Int Braz J Urol. 2017; 43: 966-73

Submitted for publication:

January 18, 2017

Accepted after revision:

March 26, 2017

Published as Ahead of Print:

May 30, 2017

\section{INTRODUCTION}

In spite of using the nerve-sparing technique, erectile dysfunction (ED) is a common complication after radical prostatectomy (RP) due to neuropraxia of the cavernous nerve (1). The main reasons which cause the cavernous nerve damage during surgery include compression, tensile and thermal damage of the nerve (2). The cavernous nerve regeneration may take several months after 
surgery and such a lengthy absence of innervations may lead to structural changes within the corpus cavernousum including smooth muscle loss and fibrosis $(3,4)$. These changes have been attributed to apoptosis after RP $(5,6)$. It has been well documented that smooth muscle apoptosis occurs within 24 hours after cavernous nerve injury (7). To date, some treatment approaches such as phosphodiesterase type 5 (PDE5) inhibitors, erythropoietin, FK506 (tacrolimus) have been tested for preserving the penile vascular bed and functional integrity of the cavernous nerves following RP (3, 8-10). Although they have proven some benefits for the ability to have sexual intercourse, there is still a need for new treatment approaches to prevent the penile corporeal damage mediated cavernous nerve injury.

Dipyridamole is currently used clinically as an antithrombotic drug. It increases cAMP level by inhibiting phosphodiesterase in platelet. It blocks the re-uptake of adenosine and increases the intracellular adenosine concentration $(11,12)$. Dipyiridamole leads to vasodilatation by increasing the adenosine formation and improves tissue perfusion in combination with antiplatelet and vasodilatory effects (13). There are also some studies that demonstrated antioxidant, neuroprotective, antiapoptotic and antifibrotic effects of dipyridamole in different tissues (14-20). Based on these features, dipyridamole may show therapeutic effect on the restoration of penile corporeal tissue after nerve-sparing RP.

In this study, an animal model of cavernous nerve crush injury was chosen to mimic the partial nerve damage during nerve-sparing RP. We aimed to evaluate the effects of daily administration of dipyridamole on penile apoptosis and erectile function measured in vivo in rats with BCNI. We also investigated the expression of transforming growth factor- $\beta 1$, a well-known profibrotic cytokine that activates penile fibrosis.

\section{MATERIAL AND METHODS}

\section{Animals and drugs}

This experimental study was carried out in accordance with Karadeniz Technical University Animal Care and Ethic Committee directives and was approved by that committee. A total of 18 male Sprague-Dawley rats (weighing between 150 and 200g) were randomized into three experimental Groups; i) sham operation with exposure of bilateral cavernous nerves and no manipulation of the nerves plus dimethyl sulphoxide (DMSO) (SHAM+DMSO, n: 6); and ii) exposure of bilateral cavernous nerves and associated nerve injury plus DMSO (BCNI+DMSO, n: 6) and iii) exposure of bilateral cavernous nerves and associated nerve injury plus dipyiridamole (BCNI+DIP, n: 6). To create bilateral cavernous injury, animals were anesthetized with an intraperitoneal injection of a mixture of ketamine/xylazine $(100+10 \mathrm{mg} / \mathrm{kg})$. The prostate was exposed via a midline abdominal incision. The cavernous nerves were identified posterolateral to the prostate. Injury was induced by applying Dumont \#5 forceps (Fine Science Tools, Foster City, California, USA) to the nerve $2-3 \mathrm{~mm}$ distal to the major pelvic ganglion. The forceps were held to closure three times for 15 seconds each, causing a moderate injury $(2,21,22)$.

Following the BCNI, treatments were given according to Groups. DMSO was administered transperitoneally as a vehicle to SHAM+DMSO and BCNI+DMSO Groups for 15 days. BCNI+DIP Group received dipyiridamole (Sigma-Aldrich, St. Louis, Missouri, USA; $10 \mathrm{mg} / \mathrm{kg} /$ day) as a solution in DMSO for 15 days transperitoneally. Drug dose was determined based on a report that demonstrated a protective effect of dipyiridamole in haloperidol-induced orofacial dyskinesia (23). After a 24 hours washout period, erectile responses were measured and penile tissues collected on the fifteenth day following BCNI.

\section{Measurement of Erectile Responses in Vivo}

After the treatment period, rats were anesthetized with a transperitoneal injection of ketamine/xylazine $(100+10 \mathrm{mg} / \mathrm{kg})$ and a standard in vivo experimental protocol was conducted for evaluation of in vivo erectile response to cavernous nerve stimulation $(22,24,25)$. Researchers were not aware of whether rats received placebo or dipyridamole. The carotid artery was cannulated to measure mean arterial pressure (MAP). The right penile crura was exposed and a 25G needle, connected to PE-50 tubing with 250U/mL heparin, 
was inserted to measure intracavernosal pressure (ICP). The cavernous nerve was identified and distal portion of nerve crushing area was stimulated with a square pulse stimulator (Grass Instruments, Quincy, Massachusetts, USA) at a frequency of $20 \mathrm{~Hz}$ and pulse width of 50 seconds. The application of 2, 4, 6, and 8 volts was used to achieve a significant erectile response. The duration of stimulation was 1 minute with rest periods of 5 to 10 minutes between subsequent stimulations. MAP and ICP were measured with a pressure transducer (Deltran, Utah Medical Products Inc. Midvale, Utah, USA) connected to a data acquisition system (ADInstruments, Colorado Springs, California, USA). Total erectile response or total ICP was determined by the area under the erectile curve (AUC; mmHg.sec) from the beginning of cavernous nerve stimulation until the ICP pressure returned to baseline or pre-stimulation pressures. The ratio between the maximal ICP and MAP obtained at the peak of erectile response was calculated to normalize for variations in systemic blood pressure. These methods have been previously described $(22,24)$.

\section{Measurement of Rat Transforming Growth} Factor- $\beta 1$ (TGF- $\beta 1$ ) Levels

Levels of rat TGF- $\beta 1$ levels were determined by enzyme-linked immunosorbent assay kit (eBioscience-Ref No: BMS623/3, Lot No: 83382003, San Diego, California, USA), according to the manufacturer's protocols. The absorbance of samples was measured at 450nm using VERSA max tunable microplate reader (Designed by Molecular Devices, California, USA). The results were expressed as pg TGF- $\beta 1$ per $\mathrm{mL}$.

\section{TUNEL assay}

Tissue samples from the mid-shaft of the penis were harvested ( $n=10$ /group), fixed in 10\% formaldehyde, embedded in paraffin, and cut in $5 \mu \mathrm{m}$ sections. Terminal deoxynucleotidyl transferase (TdT) deoxyuridine triphosphate nick end labeling assay (TUNEL) method was applied to determine the number of apoptotic cells both in smooth muscle cells and collagen fibers. TUNEL staining of sections was performed using an in situ cell death detection kit (AP kit; Roche, Mannheim,
Germany), in accordance with the manufacturer's instructions. Endogenous peroxidase activity was blocked in 3\% hydrogen peroxide. Color was then developed with a 3,3'-diaminobenzidine including kit (DAB, Sigma, St Louis, Missouri, USA). Two independent observers, blinded to the treatment regimen, separately evaluated apoptotic cells. Collagen fiber and muscle cells with brown nuclei were evaluated as apoptotic. TUNEL-positive cells were counted in five different fields of connective tissue and smooth muscle cells separately with 400X magnification. Quantification of TUNEL-positive cells was performed using the Analysis 5 Research program (Olympus Soft Imaging Solutions, Munster, Germany). The ratio of apoptotic nuclei to total number of nuclei was presented as the apoptotic index (AI) $(26,27)$.

\section{Statistical analysis}

The statistical analyses were performed with a computer software package (GraphPad Prism ${ }^{\mathrm{TM}}$ software version 5.0, La Jolla, California, USA). Data were expressed as mean \pm standard error of the mean (SEM). Differences between multiple Groups were compared by Kruskal-Wallis analysis of variance. Post-Hoc analyses were done by Mann-Whitney test with Bonferroni adjustment. P value of less than 0.05 was considered statistically significant.

\section{RESULTS}

Following the BCNI, a total of 18 rats were treated with dipyridamole and placebo (DMSO) according to groups for 15 days. Mean body weights were $320.7 \pm 10.02 \mathrm{~g}$ in SHAM+DMSO Group, $359.7 \pm 29.04 \mathrm{~g}$ in BCNI+DMSO Group and $377.8 \pm 25.96 \mathrm{~g}$ in BCNI+DIP Group. There were no differences in weight among the Groups at the end of the treatment ( $p>0.05)$.

There were no differences on baseline MAP and ICP levels among the Groups (respectively, $p>0.05$ and $p>0.05$ ). After right cavernous nerve was revealed, electrical stimulations were applied for 2, 4, 6 and 8 volts respectively to assess erection quality. Both Total ICP and ICP/MAP ratio decreased in rats with BCNI in both BCNI+DMSO and $\mathrm{BCNI}+\mathrm{DIP}$ Groups as compared to sham operated rats 
( $p<0.05)$. The decreased response in both total ICP and ICP/MAP of nerve injured rats were correlated for all voltages $(2,4,6$ and $8 \mathrm{v})$ stimulation. After 15-day treatment with dipyridamole, there was no significant improvement in erectile response of rats in BCNI+DIP Group compared to placebo treated rats $(p>0.05)$. Total ICP and ICP/MAP ratio of Groups are shown in Table-1 and Figure-1.

Penile corporal tissues of rats were evaluated biochemically in terms of TGF- $\beta 1$ levels (Table-2). Fifteen days after crush injury of cavernous nerves, there was an increase in TGF- $\beta 1$ levels of BCNI+DMSO Group compared to SHAM+DMSO Group $(\mathrm{p}<0.05)$. Dipyridamole treatment led to decrease in TGF- $\beta 1$ levels of rats in BCNI+DIP Group and there was no statistical difference between BCNI+DIP Group and SHAM+DMSO Group ( $>$ >0.05).
Penile apoptosis was evaluated by TUNEL method (Table-2 and Figure-2). A significant increased level of TUNEL positive cells in muscle cells and connective tissue of rats with BCNI was found compared to sham operated rats $(p<0.05)$. The fifteen-day treatment with dipyridamole led to reduced penile apoptosis in rats with BCNI and there were no significant differences when compared to SHAM+DMSO Group ( $p>0.05)$.

\section{DISCUSSION}

The purpose of the present study was to evaluate dipyridamole as a potential treatment agent of post-radical prostatectomy ED. A rat model of cavernous nerve crash injury was chosen to assess this hypothesis $(8,9,28,29)$.

Table 1-Shows voltage-dependenterectile responses as measured by total ICP (area under the erectile curve [AUC; $\mathrm{mmHg} \cdot \mathbf{s e c}$ ]).

\begin{tabular}{lcccc}
\hline & SHAM+DMSO & BCNI+DMSO & BCNI+DIP & $\mathrm{P}$ \\
\hline $2 \mathrm{v}$ & $2743 \pm 322.9$ & $915.5 \pm 222.0$ & $575.2 \pm 132.3$ & $\mathrm{P}<0.05^{\star}$ \\
$4 \mathrm{v}$ & $3318 \pm 273.8$ & $1356 \pm 216.1$ & $1247 \pm 196.1$ & $\mathrm{P}<0.05^{\star}$ \\
$6 \mathrm{v}$ & $3766 \pm 188.7$ & $1409 \pm 202.4$ & $1461 \pm 202.1$ & $\mathrm{P}<0.05^{\star}$ \\
$8 \mathrm{v}$ & $3485 \pm 191.3$ & $1284 \pm 195.4$ & $1606 \pm 253.2$ & $\mathrm{P}<0.05^{\star}$ \\
\hline
\end{tabular}

DMSO = dimethyl sulphoxide; $\mathbf{D I P}=$ dipyridamole; $\mathbf{B C N I}=$ bilateral cavernous nerves injury

${ }^{*}=p<0.05$ (SHAM+DMSO vs. BCNI+DMSO, SHAM+DMSO vs. BCNI+DIP)

Figure 1 - Bar graph shows voltage-dependent erectile responses as a ratio of the intracavernosal pressure (ICP) to mean arterial pressure (MAP).



${ }^{*}=p<0.05($ SHAM+DMSO vs. BCNI+DMSO, SHAM+DMSO vs. BCNI+DIP)

ns $=p>0.05(B C N I+D M S O$ vs. BCNI+DIP $)$ 
Table 2 - Shows the findings of TGF- $\beta 1$ and penile corporal apoptosis fifteen days after bilateral cavernous nerves injury.

\begin{tabular}{lcccc}
\hline & SHAM+DMSO & BCNI+DMSO & BCNI+DIP & $p$ \\
\hline TGF- $\beta 1(\mathrm{pg} / \mathrm{mL})$ & $17950 \pm 129$ & $21490 \pm 2035$ & $19380 \pm 432$ & $<0.05^{\star}$ \\
Apoptotic index in smooth muscle (\%) & $23.50 \pm 0.80$ & $55.33 \pm 1.68$ & $34.17 \pm 1.47$ & $<0.05^{\star}$ \\
Apoptotic index in connective tissue (\%) & $55.40 \pm 1.327$ & $70.67 \pm 1.229$ & $68.33 \pm 1.45$ & $<0.05^{\star}$ \\
\hline
\end{tabular}

TGF- $\boldsymbol{\beta 1}$ = transforming growth factor- $\beta 1 ; \mathbf{D M S 0}=$ dimethyl sulphoxide; $\mathbf{D I P}=$ dipyridamole; $\mathbf{B C N I}=$ bilateral cavernous nerves injury.

* $=$ SHAM+DMSO vs. BCNI+DMSO ( $p<0.05)$; SHAM+DMSO vs. BCNI+DIP ( $>>0.05) ; B C N I+D M S O$ vs. BCNI+DIP $(p>0.05)$

Figure 2 - Corpus cavernousum sections stained with the TUNEL technique (original magnification 400x).

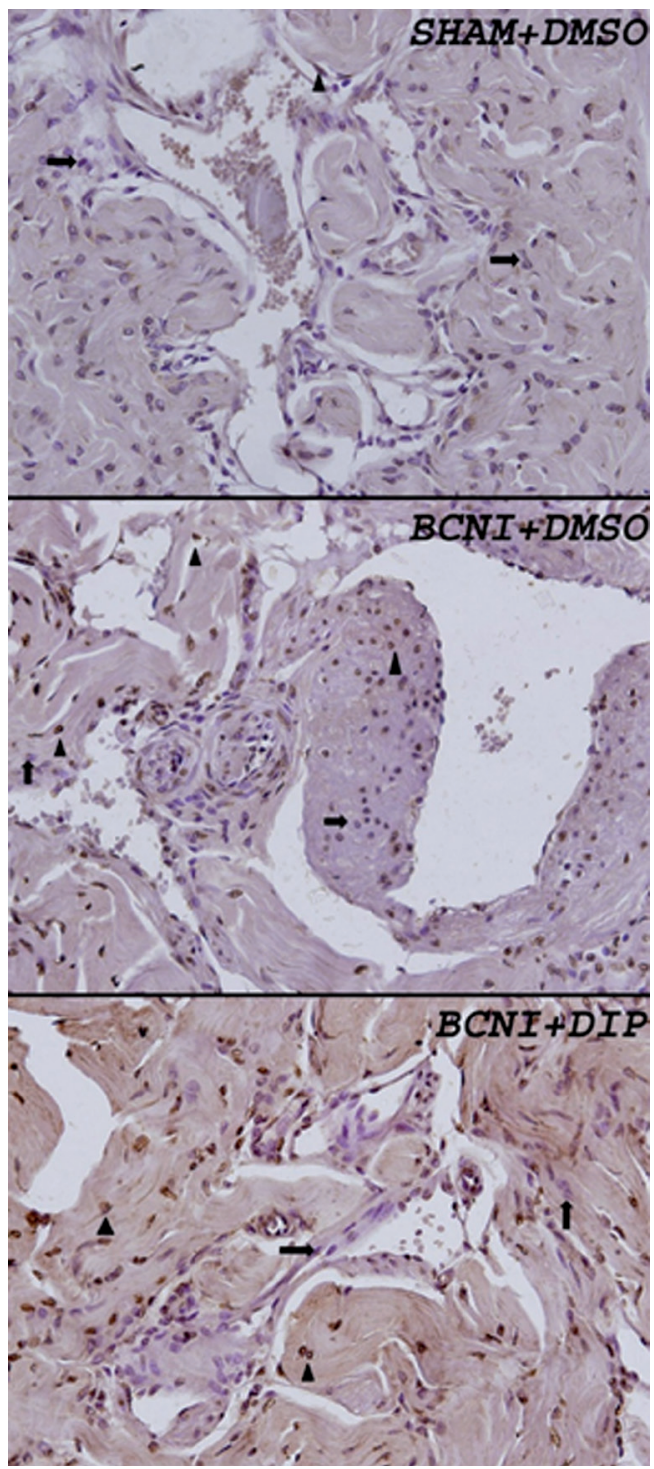

$\Delta=$ Apoptotic cells; $\uparrow=$ Normal cells
Despite advances in nerve-sparing radical prostatectomy technique, many patients are experiencing the loss of erectile function during postoperative period $(22,30)$. Penile fibrosis as a result of cavernous nerve injury has been well determined in both experimental models and in patients $(7,31)$. Neuropraxia causes an increased apoptosis and fibrosis in both penile smooth muscle cells and endothelium $(5,6)$. Additionally, an increase in reactive oxygen species and TGF- $\beta 1$ over expression has been reported (31-33). It has been also reported that BCNI causes a reduction in nitric oxide synthase (NOS) containing nerve fiber in animal models (34).

Even though nitric oxide (NO) is the principal relaxant of the penile smooth muscle cells, multiple other factors, either neuronal or vascular, have also been shown to modulate penile erection (35-37). Adenosine, like NO, is a potent vasodilator and its role in penile erection has been investigated in many studies which showed that intracavernous injection of adenosine resulted in tumescence and penile erection (38-41). Adenosine induced vasodilatation is mediated by increased intracellular cyclic adenosine mono phosphate (cAMP) levels in vascular smooth muscle cells via $A_{2}$ receptor signaling $(42,43)$. Along with normal penile erection, adenosine signaling has also been found to be critical in erectile disorders. Gur and Ozturk suggested a greater role for adenosine as a modulator in human corpus cavernousum than in the corporal tissue of rats (44). The impairment of nonadrenergic noncholinergic neurotransmission and endothelial dysfunction due to diabetes, chronic renal failure, and hypothyroidism, seem to contribute toward erectile dysfunction, but adenosine induced relaxation of 
corpus cavernousum is preserved, indicating a potential therapeutic role for adenosine (45-47). Faria et al. observed partial resistance of corpus cavernousum in men with vasculogenic impotence to adenosine induced relaxation and showed that dysfunctional $\mathrm{A}_{2 \mathrm{~B}}$ receptors, supposedly on the endothelium, are the cause for the signaling impairment (48). Similarly, Kilic et al. observed full erection and no side effect with high dosage of intracorporeal adenosine injection in vasculogenic impotence in human (49). Chiang et al. and Filipi et al. evaluated the effect of intracorporeal injection of adenosine in impotent men which caused increased cavernosal arterial flow and resulted in suboptimal erection $(50,51)$. Chiang et al. attributed the suboptimal erection upon adenosine injection to the rapid degradation of adenosine by adenosine deaminase (50).

Dipyridamole is an adenosine transport inhibitor which is currently in use clinically as an antithrombotic drug. There are also some studies that demonstrated antioxidant, neuroprotective, antiapoptotic and antifibrotic effects of dipyridamole in different tissues (14-20). In a study to investigate the antioxidant properties of dipyridamole, Vargas and colleagues have found that dipyridamole probably clears the reactive oxygen radicals released from human polymorphonuclear leukocytes (ROS) (15). Also, it has been reported that dipyridamole protects the erythrocyte membranes from oxidation (52). Another animal study showed that dipyridamole protects the liver cells from the damage of ischemia/reperfusion injury (16). In addition, Garcia-Bonilla et al. identified the neuroprotective effects of dipyridamole in experimental models of cerebral ischemia in rats (17).

Dipyridamole increases cAMP level by inhibiting phosphodiesterase in platelet. It blocs the re-uptake of adenosine and increases the intracellular adenosine concentration $(11,12)$. Dipyiridamole leads to vasodilatation by increasing the adenosine formation and improves tissue perfusion (13). According to this knowledge, in this study, we anticipated that phosphodiesterase inhibition and adenosine accumulation by dipyridamole might contribute penile erection. But we did not see any different among the Groups after fifteen-day dipyridamole treatment. This failure might be caused by a short time for the recovery of injured cavernous nerves.

Hung et al. reported that dipyridamole has antifibrotic effect and inhibits collagen gene expression induced by TGF- $\beta$ in human peritoneal mesothelial cells (20). In previous reports of animal model of BCNI, penile corporeal fibrosis has been linked to over expression of TGF- $\beta 1$ (53, 54). In present study, BCNI led to increase TGF- $\beta 1$ levels and fifteen-day dipyridamole treatment reduced its expression. This effect might help to reduce penile fibrosis and preserve smooth muscle cells.

Some reports have shown that dipyridamole has an antiapoptotic effect. Schrier and Yang reported that dipyridamole significantly blocks the activity of caspases which play an important role in the mechanism during the apoptotic cell death $(18,19)$. In our study, although we did not investigate caspase pathway, dipyridamole reduced penile corporeal apoptosis determined by TUNEL technique.

There are certainly a few limitations that are worth noting with this study. The main limitation of our study is that we have only used one time point and pharmacological dose to evaluate the therapeutic effect of dipyridamole. There is a possibility to get various outcomes with longer duration of treatment and/or different pharmacological dose. Additionally, this study did not evaluate other possible effects of dipyridamole to contribute erectile function recovery such as the antioxidant and neuroprotective effects.

\section{CONCLUSIONS}

Although fifteen-day dipyridamole treatment has failed to improve erectile function in rats with BCNI, the decline in both TGF- $\beta 1$ levels and apoptotic indices with treatment may be helpful in protecting penile morphology after cavernous nerve injury. Further studies are required to understand the effect of different pharmacological dose and long term treatment with dipyridamole especially in terms of penile hemodynamic response. 


\section{ACKNOWLEDGMENTS}

This study was supported by Karadeniz Technical University Scientific Research Project Administration.

\section{CONFLICT OF INTEREST}

None declared.

\section{REFERENCES}

1. Bivalacqua TJ, Pierorazio PM, Su LM. Open, laparoscopic and robotic radical prostatectomy: optimizing the surgical approach. Surg Oncol. 2009;18:233-41.

2. Burnett $A L$, Allaf ME, Bivalacqua TJ. Erythropoietin promotes erection recovery after nerve-sparing radical retropubic prostatectomy: a retrospective analysis. J Sex Med. 2008;5:2392-8.

3. Rambhatla A, Kovanecz I, Ferrini M, Gonzalez-Cadavid NF, Rajfer J. Rationale for phosphodiesterase 5 inhibitor use post-radical prostatectomy: experimental and clinical review. Int J Impot Res. 2008;20:30-4.

4. Burnett AL. Erectile dysfunction following radical prostatectomy. JAMA. 2005;293:2648-53.

5. Podlasek CA, Zelner DJ, Bervig TR, Gonzalez CM, McKenna KE, McVary KT. Characterization and localization of nitric oxide synthase isoforms in the BB/WOR diabetic rat. J Urol. 2001;166:746-55.

6. Klein LT, Miller MI, Buttyan R, Raffo AJ, Burchard M, Devris $G$, et al. Apoptosis in the rat penis after penile denervation. $J$ Urol. 1997;158:626-30.

7. User HM, Hairston JH, Zelner DJ, McKenna KE, McVary KT. Penile weight and cell subtype specific changes in a postradical prostatectomy model of erectile dysfunction. J Urol. 2003;169:1175-9.

8. Sezen SF, Blackshaw S, Steiner JP, Burnett AL. FK506 binding protein 12 is expressed in rat penile innervation and upregulated after cavernous nerve injury. Int J Impot Res. 2002;14:506-12.

9. Valentine H, Chen Y, Guo H, McCormick J, Wu Y, Sezen SF, et al. Neuroimmunophilin ligands protect cavernous nerves after crush injury in the rat: new experimental paradigms. Eur Urol. 2007;51:1724-31.

10. Vignozzi L, Filippi S, Morelli A, Ambrosini S, Luconi M, Vannelli $\mathrm{GB}$, et al. Effect of chronic tadalafil administration on penile hypoxia induced by cavernous neurotomy in the rat. J Sex Med. 2006;3:419-31.

11. Harker LA, Kadatz RA. Mechanism of action of dipyridamole. Thromb Res Suppl. 1983:4:39-46.
12. Schaper W. Dipyridamole, an underestimated vascular protective drug. Cardiovasc Drugs Ther. 2005;19:357-63.

13. Chakrabarti S, Vitseva O, Iyu D, Varghese S, Freedman JE. The effect of dipyridamole on vascular cell-derived reactive oxygen species. J Pharmacol Exp Ther. 2005;315:494-500.

14. Iuliano L, Ghiselli A, Alessandri C, Bonavita MS, Violi F. Superoxide anion scavenging property of dipyridamole. Thromb Haemost. 1989;61:149.

15. Vargas F, Rivas C, Díaz Y, Contreras N, Silva A, Ojeda LE, et al. Antioxidant properties of dipyridamole as assessed by chemiluminescence. Pharmazie. 2003;58:817-23.

16. Taniguchi M, Magata S, Suzuki T, Shimamura T, Jin MB, lida J, et al. Dipyridamole protects the liver against warm ischemia and reperfusion injury. J Am Coll Surg. 2004;198:758-69.

17. García-Bonilla L, Sosti V, Campos M, Penalba A, Boada C, Sumalla $M$, et al. Effects of acute post-treatment with dipyridamole in a rat model of focal cerebral ischemia. Brain Res. 2011;1373:211-20.

18. Schrier SM, van Tilburg EW, van der Meulen H, ljzerman AP, Mulder GJ, Nagelkerke JF. Extracellular adenosineinduced apoptosis in mouse neuroblastoma cells: studies on involvement of adenosine receptors and adenosine uptake. Biochem Pharmacol. 2001;61:417-25.

19. Yang D, Yaguchi T, Nakano T, Nishizaki T. Adenosineinduced caspase-3 activation by tuning Bcl-XL/DIABLO/ IAP expression in HuH-7 human hepatoma cells. Cell Biol Toxicol. 2010;26:319-30.

20. Hung KY, Chen CT, Huang JW, Lee PH, Tsai TJ, Hsieh BS. Dipyridamole inhibits TGF-beta-induced collagen gene expression in human peritoneal mesothelial cells. Kidney Int. 2001;60:1249-57.

21. Canguven 0 , Burnett $A$. Cavernous nerve injury using rodent animal models. J Sex Med. 2008;5:1776-85.

22. Gratzke C, Strong TD, Gebska MA, Champion HC, Stief $\mathrm{CG}$, Burnett AL, et al. Activated RhoA/Rho kinase impairs erectile function after cavernous nerve injury in rats. J Urol. 2010;184:2197-204.

23. Bishnoi M, Chopra K, Kulkarni SK. Protective effect of adenosine reuptake inhibitors in haloperidol-induced orofacial dyskinesia and associated behavioural, biochemical and neurochemical changes. Pharmacology. 2007;79:17183.

24. Bivalacqua TJ, Champion HC, Usta MF, Cellek S, Chitaley K, Webb RC, et al. RhoA/Rho-kinase suppresses endotelial nitric oxide synthase in the penis: a mechanism for diabetesassociated erectile dysfunction. Proc Natl Acad Sci U S A. 2004;101:9121-6.

25. Bivalacqua TJ, Deng W, Kendirci M, Usta MF, Robinson C Taylor BK, et al. Mesenchymal stem cells alone or ex vivo gene modified with endothelial nitric oxide synthase reverse age-associated erectile dysfunction. Am J Physiol Heart Circ Physiol. 2007;292:H1278-90. 
26. Mulhall JP, Müller A, Donohue JF, Mullerad M, Kobylarz K, Paduch DA, et al. The functional and structural consequences of cavernous nerve injury are ameliorated by sildenafil citrate. $\mathrm{J}$ Sex Med. 2008;5:1126-36.

27. Bond CW, Angeloni NL, Harrington DA, Stupp SI, McKenna KE, Podlasek CA. Peptide amphiphile nanofiber delivery of sonic hedgehog protein to reduce smooth muscle apoptosis in the penis after cavernous nerve resection. J Sex Med. 2011;8:78-89.

28. Sezen SF, Lagoda G, Burnett AL. Role of immunophilins in recovery of erectile function after cavernous nerve injury. J Sex Med. 2009;6(Suppl 3):340-6.

29. Lagoda G, Sezen SF, Burnett AL. FK506 and rapamycin neuroprotect erection and involve different immunophilins in a rat model of cavernous nerve injury. J Sex Med. 2009;6:1914-23.

30. Klotz L. Advances in nerve sparing for radical prostatectomy. Urology. 1999;54:956-9.

31. Iacono F, Giannella R, Somma P, Manno G, Fusco F, Mirone V. Histological alterations in cavernous tissue after radical prostatectomy. J Urol. 2005;173:1673-6.

32. Ferrini MG, Davila HH, Kovanecz I, Sanchez SP, GonzalezCadavid NF, Rajer J. Vardenafil prevents fibrosis and loss of corporal smooth muscle that occurs after bilateral cavernosal nerve resection in the rat. Urology. 2006;68:429-35.

33. Leungwattanakij S, Bivalacqua TJ, Usta MF, Yang DY, Hyun JS, Champion $\mathrm{HC}$, et al. Cavernous neurotomy causes hypoxia and fibrosis in rat corpus cavernosum. J Androl. 2003:24:239-45.

34. Jung GW, Kwak JY, Yoon S, Yoon JH, Lue TF. IGF-I and TGFbeta2 have a key role on regeneration of nitric oxide synthase (NOS)-containing nerves after cavernous neurotomy in rats. Int J Impot Res. 1999;11:247-59.

35. Andersson KE. Pharmacology of penile erection. Pharmacol Rev. 2001;53:417-50.

36. Kun A, Kiraly I, Pataricza J, Marton Z, Krassoi I, Varro A, et al. C-type natriuretic peptide hyperpolarizes and relaxes human penile resistance arteries. J Sex Med. 2008;5:1114-25.

37. Lin CS. Phosphodiesterase type 5 regulation in the penile corpora cavernosa. J Sex Med. 2009;6 (Suppl 3):203-9.

38. Prieto D. Physiological regulation of penile arteries and veins. Int J Impot Res. 2008;20:17-29.

39. Tostes RC, Giachini FR, Carneiro FS, Leite R, Inscho EW, Webb RC. Determination of adenosine effects and adenosine receptors in murine corpus cavernosum. J Pharmacol Exp Ther. 2007;322:678-85.

40. Mi T, Abbasi S, Zhang H, Uray K, Chunn JL, Xia LW, et al. Excess adenosine in murine penile erectile tissues contributes to priapism via A2B adenosine receptor signaling. J Clin Invest. 2008;118:1491-501.

41. Christ GJ, Richards S, Winkler A. Integrative erectile biology: the role of signal transduction and cell-to-cell communication in coordinating corporal smooth muscle tone and penile erection. Int J Impot Res. 1997;9:69-84.
42. Tager AM, LaCamera P, Shea BS, Campanella GS, Selman M, Zhao Z, et al. The Iysophosphatidic acid receptor LPA1 links pulmonary fibrosis to lung injury by mediating fibroblast recruitment and vascular leak. Nat Med. 2008;14:45-54.

43. Olsson RA, Pearson JD. Cardiovascular purinoceptors. Physiol Rev. 1990;70:761-845.

44. Gür $\mathrm{S}$, Oztürk B. Altered relaxant responses to adenosine and adenosine 5'-triphosphate in the corpus cavernosum from men and rats with diabetes. Pharmacology. 2000;60:105-12.

45. Carneiro FS, Giachini FR, Lima VV, Carneiro ZN, Leite R, Inscho EW, et al. Adenosine actions are preserved in corpus cavernosum from obese and type II diabetic $\mathrm{db} / \mathrm{db}$ mouse. $J$ Sex Med. 2008:5:1156-66.

46. Kilicarslan H, Yildirim S, Bagcivan I, Ayan S, Sarac B, Sarioglu Y. Effect of chronic renal failure on the purinergic responses of corpus cavernosal smooth muscle in rabbits. BJU Int. 2002;90:596-600.

47. Yildirim MK, Bagcivan I, Sarac B, Kilicarslan H, Yildirim S, Kaya T. Effect of hypothyroidism on the purinergic responses of corpus cavernosal smooth muscle in rabbits. Int Urol Nephrol. 2008;40:691-9.

48. Faria $M$, Magalhães-Cardoso $T$, Lafuente-de-Carvalho JM, Correia-de-Sá P. Corpus cavernosum from men with vasculogenic impotence is partially resistant to adenosine relaxation due to endothelial $A(2 B)$ receptor dysfunction. $J$ Pharmacol Exp Ther. 2006;319:405-13.

49. Kiliç S, Salih M, Anafarta K, Baltaci S, Koşar A. Adenosine: a new agent in the diagnosis of impotence. Int $\mathrm{J}$ Impot Res. 1994;6:191-8.

50. Chiang PH, Wu SN, Tsai EM, Wu CC, Shen MR, Huang CH, et al. Adenosine modulation of neurotransmission in penile erection. Br J Clin Pharmacol. 1994;38:357-62.

51. Filippi S, Mancini M, Amerini S, Bartolini M, Natali A, Mancina $\mathrm{R}$, et al. Functional adenosine receptors in human corpora cavernosa. Int J Androl. 2000;23:210-7.

52. Kusmic C, Picano E, Busceti CL, Petersen C, Barsacchi R. The antioxidant drug dipyridamole spares the vitamin $\mathrm{E}$ and thiols in red blood cells after oxidative stress. Cardiovasc Res. 2000;47:510-4.

53. Cabrini MR, Sezen SF, Lagoda G, Segal RL, Feng Z, Andreoni $\mathrm{C}$, et al. Fibrotic protein expression profiles in penile tissue of patients with erectile dysfunction. Urology. 2013;82:975.e1-6.

54. El-Sakka Al, Yassin AA. Amelioration of penile fibrosis: myth or reality. J Androl. 2010;31:324-35.

Correspondence address: Omer Kutlu, MD

Associate Professor of Urology Department of Urology School of Medicine, Akdeniz University Antalya, 07058, Turkey

Telephone: + 90242 249-6825

E-mail: dromerkutlu@yahoo.com.tr 